\title{
Genetic evidence for repression of somatic $P$ element movements in Drosophila melanogaster consistent with a role for the KP element
}

\author{
J. F. Y. BROOKFIELD \\ Department of Genetics, University of Nottingham, Queens Medical Centre, Nottingham NG7 2UH, U.K.
}

\begin{abstract}
The P family of transposable elements in Drosophila melanogaster has, since its introduction into $D$. melanogaster populations in this century, diversified into a number of internally deleted forms. One of these, the KP element, is abundant in the genomes of flies from populations from Asia, Europe and Africa. There is some evidence that this sequence can act as a repressor of transposition. We have studied a mutation, singed ${ }^{\text {very weak }}\left(s n^{v w}\right)$, in which a $\mathrm{KP}$ element is one of two $\mathrm{P}$ elements inserted into the $5^{\prime}$ exon of the $\mathrm{X}$-linked singed gene. These elements can be mobilized by a trans-acting dominant mutation, $M o$, with a maternal effect, on the second chromosome. The rate of somatic reversion of $s n^{\nu w}$ induced by $M o$ is reduced threefold if the mother herself possesses $s n^{v w}$ on her X chromosomes. This implies that $s n^{v w}$ may be responsible for a form of repression of $\mathrm{P}$ element movements. The cause of this effect may be related to transcription of the KP element in $s n^{\nu w}$. However, an effect of other genomic $\mathrm{P}$ elements in the repression of somatic reversion of $s n^{\nu w}$ cannot be entirely excluded.
\end{abstract}

Keywords: Drosophila melanogaster, P elements, transposable elements.

\section{Introduction}

The $\mathrm{P}$ family of transposable elements is a class of transposable elements in Drosophila melanogaster that move via a DNA mechanism (Engels et al., 1990; Gloor et al., 1991; Nassif et al., 1994). This movement induces a syndrome of traits including male recombination and high temperature sterility that have been called P-M hybrid dysgenesis. Since its invasion of the Drosophila melanogaster genome early in this century (Anxolabéhère et al., 1988) the $\mathrm{P}$ element has evolved into a heterogeneous family of sequences, most of which differ from the ancestral full-length sequence by internal deletions (for review see Engels, 1989). The full-length element encodes the P transposase, which is required in trans for all $\mathrm{P}$ element movements. The collections of $\mathrm{P}$ elements in the genomes of $D$. melanogaster populations from Europe, Asia and Africa, are dominated by a particular deletion derivative called the KP element (Black et al., 1987). This has a single internal deletion removing nucleotides 807 to 2561 of the 2907 base pair P element sequence (O'Hare \& Rubin 1983).
Whereas full-length $\mathrm{P}$ elements produce transposase in the germline, a number of systems in which transposition is repressed are also produced by various kinds of $P$ elements. In somatic cells splicing of the transcript from the element is incomplete (Laski et al., 1986; Laski \& Rubin, 1989; Siebel et al., 1992), and the third intron is retained. The truncated protein produced, which lacks amino acids specified by the fourth exon of the transposase gene, has also been shown to be a repressor of transposition.

A number of repression systems are known that operate in the germline. These can be monitored by screening the attenuation of the high temperature sterility caused by hybrid dysgenesis, or by looking at the reversion rate of a double $\mathrm{P}$ element insertion mutation in the singed gene called singed ${ }^{\text {weak }}$ (Engels, 1979; Roiha et al., 1988). One germline repression system is P-cytotype, which is maternally inherited. P-cytotype appears often to be the result of a class of $\mathrm{P}$ elements which lack some or all of the fourth exon. The structure and properties of these, so-called class I, repressors have received considerable study (Gloor et al., 1993). Sometimes, full- 
length $\mathrm{P}$ elements appear capable of eliciting P-cytotype by virtue of their genomic position. A naturally-occurring pair of such elements on the tip of the $\mathrm{X}$ chromosome have been shown to be capable of causing P-cytotype (Ronsseray et al., 1991). Molecular studies using the $P$ element promoter attached to a lac $Z$ reporter gene have shown that P-cytotype results in a reduction in the level of transcription from a $\mathrm{P}$ promoter (Lemaitre \& Coen, 1991; Lemaitre et al., 1993). There is also evidence that shorter deleted elements can also cause repression of transposition. For these, the evidence argues against a maternally-inherited repression, but for repression that is zygotic or through a maternal effect arising in a single generation. Much the most abundant internally deleted $\mathrm{P}$ element in populations from the old world is one called the KP element (Black et al., 1987). The KP element has been found to increase its genomic copy number rapidly in laboratory strains, provided that full-length $\mathrm{P}$ elements are present (Jackson et al., 1988). These authors interpret this increase as driven by the natural selection resulting from a repressing KP element's capacity to reduce the sterility effect of hybrid dysgenesis. Simulations have shown that inactive or repressingelements can invade populations of intact dysgenesis-inducing elements under a wide range of conditions (Brookfield, 1991). The data concerning KP elements' capacity to repress $\mathrm{P}$ element movements are, however, highly heterogeneous. Some strong $\mathrm{P}$ strains, showing no chromosomally-inherited repression, contain large numbers of $\mathrm{KP}$ elements (Monastirioti et al., 1988). Other strains, with high levels of chromosomally-determined repression, lack KP elements (Heath \& Simmons, 1991). A survey of the repressing properties of single deleted $\mathrm{P}$ elements (Rasmusson et al., 1993) showed that although two of the three KP elements tested repressed singed $d^{\text {weak }}$ reversion in the presence of a $\mathrm{P}$ transposase source, and a similar length $\mathrm{P}$ sequence did not, the strongest repression was elicited by a much rarer and shorter element, called SP. Furthermore, one of three KP elements tested showed no repression. One explanation for the capricious nature of repression could be that it depends upon the level of transcription of the element, which will itself by largely dependent on the presence of transcriptional enhancers near the target site (a phenomenon exploited in the 'enhancer trap' technique (O'Kane \& Gehring, 1987)). Similarly, a KP element inserted at 47D on the second chromosome is associated with a strong repression of $\mathrm{P}$ element movements (Higuet et al., 1992), but several lines of evidence suggest that this may be the result of a mutation in a host gene.

In the mutation singed ${ }^{\text {very weak }}$ (or $s n^{v w}$ ), two deleted $\mathrm{P}$ elements are inserted into the singed gene in a tail-to-tail orientation. The phenotype is very weak curvature of the bristles, less profound than for singed $^{\text {weak }}$. This mutation can show what is, for $\mathrm{P}$ element insertion mutations, the very unusual property of being somatically unstable. $s n^{\nu \omega}$ can revert somatically to patches of strong singed tissue in a very weakly singed phenotypic background, but only in the sons of females which have a dominant maternal effect mutation, which we have called Mo (for mosaicism) (Brookfield \& Lewis, 1989). The two P elements in $s n^{v w}$ are apparently inserted next to each other save for the 8 base pair target sequence duplicated between them, at base pair 1580 of the singed sequence (Paterson \& O'Hare, 1991; Ortori et al., 1994). This is part of the $5^{\prime}$ untranslated exon of singed (Roiha et al., 1988; Paterson \& O'Hare, 1991). The larger of the two elements is transcribed in the same direction as the singed gene, and has an internal deletion from 807 to 2561 , which shows it to be a KP element. The smaller, downstream, element is transcribed in the opposite direction to the first and to singed, and has an internal deletion removing base pairs 204-2500.

Under the influence of zygotic or maternal $M o$, or both, the $s n^{\nu w}$ mutation reverts in the male germ line at 2-7 per cent per generation, to give products in which the smaller or the larger element is precisely deleted. These products have strong singed (below called singed $d^{\text {extreme}}$, or $s n^{e}$ ), and pseudo-wild-type $\left(s n^{+}\right)$phenotypes, respectively. The generation of mosaic $s n^{e}$ patches is also caused by somatic excision of the smaller element (Ortori et al., 1994).

Mo maps between map positions 59-64 in the second chromosome, which implies that it is in chromosomal division 47. A strong band of $\mathrm{P}$ element homology at $47 \mathrm{C}$ has been identified through in situ hybridization to Mo chromosomes (J. F. Y. Brookfield et al., unpublished data). Thus, an economical explanation of the nature of $M o$ is that it is a modified $\mathrm{P}$ element which puts a form of $\mathrm{P}$ transposase with an usually long half-life into the egg, which then causes precise excisions of the elements from $s n^{v w}$ in the zygote.

The combination of $s n^{v w}$ and Mo suggests a test of the repressor capacity of the KP element. $s n^{v w}$ is a highly unstable mutation which includes a KP element. This shows that the presence of a KP element in the cell cannot, by itself, strongly repress all $\mathrm{P}$ element movements. However, the repressive effects of the KP element may be dependent on whether it is transciribed. The advantage of $s n^{v w}$ is 
that the transcription of the KP element will probably be governed by the singed promoter and enhancers, and the transcription pattern of singed is known (Paterson \& O'Hare, 1991). singed is transcribed in the pupae in both males and females, but in larvae is transcribed only in ovaries. This would suggest that if the KP polypeptide product acts as a repressor, the rate of reversion of $s n^{\nu w}$ in homozygous females might be lower than the rate in hemizygous males under the same conditions. However, there might be many reasons why reversion rates in females and males could be different, quite apart from any effect of a KP protein produced in females. The number of cell generations in the female germ line will be fewer than in the male germ line. Conversely, the transcription of singed may well make the gene, and the $\mathrm{P}$ elements within it, more accessible to $\mathrm{P}$ proteins, and create a higher reversion rate. This predicted difference in rate would be independent of the particular structure of elements located at singed.

There is, however, an experiment in which the effect of female-specific transcription of singed on the reversion rate of $s n^{\nu w}$ can be studied. $s n^{\nu w}$ males can be produced in attached-X crosses, in which they receive the mutation from their fathers. They can also be produced by standard crosses in which they receive the mutation from their mothers. Mothers possessing Mo can be used in each cross, but the difference is that in the latter there will also be transcription of the KP element in the maternal germline. If this transcription of KP from $s n^{v w}$ has an effect on the power of $M o$, this could be observed through a change in the mosaicism rate of $s n^{\nu w}$ in the $F_{1}$ males. It is possible to carry out this experiment because, in keeping the $s n^{v w}$ mutation on the hemizygous $\mathrm{X}$ chromosome in males kept with attached- $X$ females, a rare nondisjunction event made it possible to establish a line in which the females were homozygous for the $s n^{v w}$ mutation. Nevertheless, this strain was, apart from the $X$ chromosomes, genetically identical to the attached$X$ strain from which it was derived. By comparison of the rates of somatic excision of $\mathrm{P}$ elements from $s n^{v w}$ in crosses using these two strains, it is possible to see the maternal effect of the $s n^{\nu w}$ allele itself on $s n^{v w}$ mosaicism in $\mathrm{F}_{1}$ males.

\section{Materials and methods}

Drosophila melanogaster strains

Strain 1. C(1) DXyf/T $(1: \mathrm{Y}) y^{+} ;$pr $b d p ; s t$ os and $y$ $s n^{v w} ; \mathrm{T}(1: \mathrm{Y}) y^{+} ; p r b d p ; s t{ }^{s} \mathrm{~s}$. This is an $\mathrm{M}^{\prime}$ strain that initially lacked $\mathrm{P}$ elements except for the male $\mathrm{X}$ chromosome, which has two deleted $\mathrm{P}$ elements inserted in $s n^{v w}$. We have since discovered ( $\mathrm{P}$. Emery, T. Robinson and J. F. Y. Brookfield, unpublished data) that the strain possesses a single form of short $\mathrm{P}$ element (of around 400 base pairs) which is located on both second and third chromosomes. This may have been derived by low level movements from the $X$ to the autosomes in males during the 4 years during which this strain has been kept. Nevertheless, the $s n^{v w}$ mutation has remained entirely stable in this strain. For a full account of the production of this strain see Ortori et al. (1994) where it is referred to as strain 6 .

Strain 2. This strain is as strain 1 but has second chromosomes heterozygous for $\mathrm{Mo} / \mathrm{pr} b \mathrm{dp}$. This strain was derived by crossing attached-X $M o$ females to strain 1 males above. $\mathrm{F}_{1} \mathrm{pr}^{+} b^{+} d p^{+}$ $M o / p r ~ b d p$ females were selected, and crossed to further strain 1 males. This crossing scheme has been repeated for more than 20 generations. In this time all material in the original $M o$ strain will have been replaced by strain 1 material, with the exception of the region of the second chromosome between $d p$ and $M o$, and the attached-X chromosomes. However, the attached-X chromosomes in this strain were originally the same as those in strain 1 , and lacked $\mathrm{P}$ elements. The linkage of $\mathrm{pr}^{+}$to $\mathrm{Mo}$ allows $\mathrm{pr}^{+}$to act as an approximate visible marker for $M o$.

Strain 3. $y s n^{v w}$; pr $b d p$; st os and $y s n^{v w} / \mathrm{T}(1: \mathrm{Y}) y^{+}$; pr $b d p$; st ${ }^{A} \mathrm{~s}$. The males and females possess the same $\mathrm{X}$ chromosome and autosomes. This strain was derived from a nondisjunction in a strain 1 male, in which two $X$ chromosomes entered the same sperm. Fertilization of a Y-bearing oocyte yielded an XXY female which then established a line in which $s n^{\nu w}$ was present in male and female $\mathrm{X}$ chromosomes, but the strain had identical autosomes to those in strain 1.

The three strains shared recent common ancestry very soon before the commencement of the experiment, which implies that the short autosomal $\mathrm{P}$ elements subsequently seen in strain 1 would have been present in strains 2 and 3 also.

\section{Crosses}

Figure 1 shows the crosses performed. Five strain 2 males were taken individually and crossed to both strain 3 and strain 1 females. From the $F_{1}$ of the former cross, two crosses were set up. Firstly, $\mathrm{pr}^{+} / \mathrm{pr}$ 
Fig. 1 Crosses in the experiment. Individual parental males (strain 2) were crossed to females from strain 3 (homozygous $s n^{v w}$ ), and females from strain 1 (attached-X with $s n^{+}$). $\mathrm{F}_{1}$ males and females from each cross were selected for $\mathrm{pr}^{+}$, and thus $\mathrm{Mo}$, and their sons examined. Cross (i) $\mathrm{F}_{2}$ males show the rate of mosaicism of $s n^{v w}$ when the mother is homozygous for $s n^{\nu w}$. The proportion of germline revertants seen in these males shows the reversion rates in their mothers' germlines. Cross (ii) and cross (iv) $\mathrm{F}_{2}$ males show the rate of reversion in the germlines of $F_{1}$ males with zygotic Mo. Cross (iii) $\mathrm{F}_{2}$ males show the rate of mosaicism in $s n^{v w}$ males with homozygous $\mathrm{sn}^{+}$mothers.

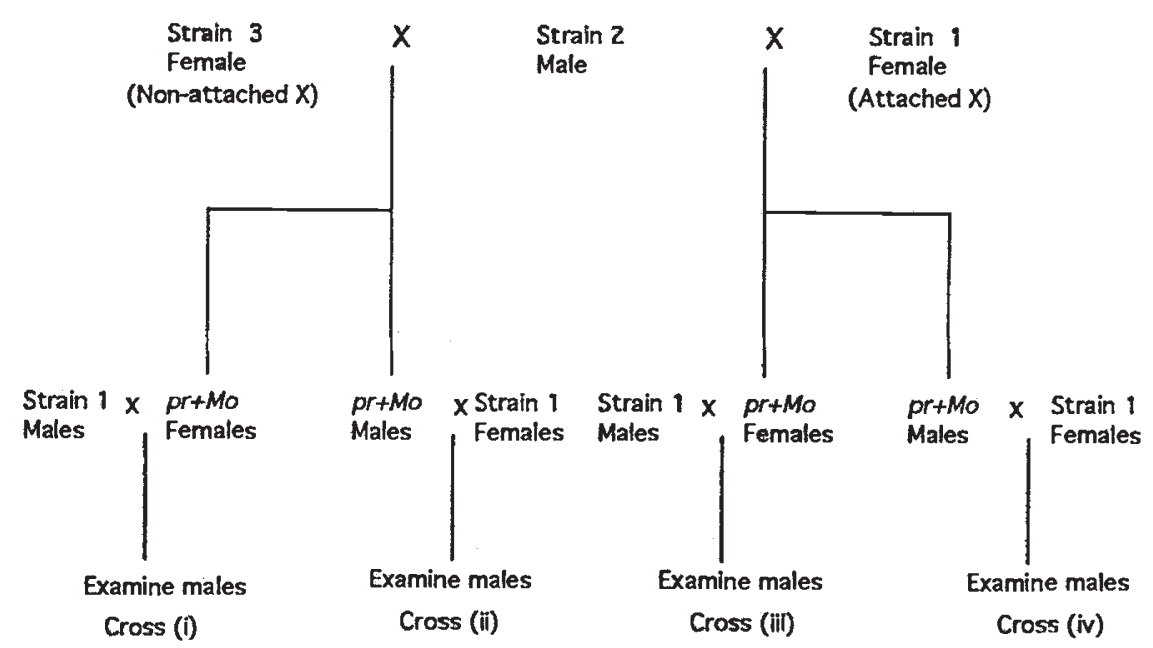

females (which possessed the Mo allele) were crossed to strain 1 males. This is referred to as cross (i) below.

Secondly, $\mathrm{pr}^{+} / p r \mathrm{~F}_{1}$ males were crossed to strain 1 females. This is referred to as cross (ii).

From the second parental cross, to strain 1, two crosses were carried out with $\mathrm{F}_{1}$ flies. $\mathrm{pr}^{+} / \mathrm{pr}$ females were crossed to strain 1 males (cross iii), and $F_{1}$ $\mathrm{pr}^{+} / \mathrm{pr}$ males were crossed to strain 1 females (cross iv). The purposes of these crosses were as follows.

Cross (i) screens the $s n^{v w}$ offspring of $M o s n^{\nu w}$ mothers for mosaicism of $s n^{\nu w}$. Furthermore, as $\mathrm{F}_{2}$ males are derived from gametes from $F_{1}$ females, examination of $F_{2}$ males measures the germline reversion rate of $s n^{\nu w}$ in these females, which possessed zygotic $M o$ but lacked maternal $M o$.

Cross (ii) examines the level of germline reversion of $s n^{\nu w}$ in males in the presence of zygotic but not maternal Mo.

Cross (iii) screens the $s n^{v w}$ offspring of $M o s n^{+}$ mothers for mosaicism of $s n^{\nu w}$.

Cross (iv) also examines the level of germline reversion of $s n^{\nu w}$ in males in the presence of zygotic but not maternal Mo. However, the $s n^{\nu w}$ allele examined in cross (ii) is derived from strain 3 , whereas that examined in cross (iv) is derived from strain 2.

Five to 20 individual crosses were carried out for each cross with each starting male, with the exception of male 1, for whom cross (iv) was not performed. The marker $\mathrm{pr}^{+}$will be in coupling with $M o$ in all $\mathrm{F}_{1}$ offspring of a given parental male, as no recombination will occur in these males. Thus, if all parental males possess $M o, M o$ will be found in all $\mathrm{F}_{1}$ flies selected though their possession of $\mathrm{pr}^{+}$. The individual males examined in the $F_{2}$ will consist of a mixture of flies heterozygous for Mo and homozygous for its absence. However, $M o$ is not required zygotically for mosaicism and the distribution of $M o$ among males in the $F_{2}$ will be the same for crosses (i) to (iv).

Flies were maintained at $22^{\circ} \mathrm{C}$ in a $12 \mathrm{~h}$ light: $12 \mathrm{~h}$ dark cycle on a standard molasses and maize meal mixture.

\section{Results}

Mosaicism was found in the $F_{2} s$ of crosses (i) and (iii) for crosses using all five parental males, indicating that all these five males indeed possessed $M o$. Thus all $\mathrm{F}_{1}$ flies selected using $\mathrm{pr}^{+}$would also possess $\mathrm{Mo}$. Male offspring from the four crosses (i), (ii), (iii) and (iv) can be divided into four classes. These are $s n^{\nu w}$ mosaics, $s n^{\nu w}$ nonmosaics, $s n^{e}$, and $s n^{+}$. The numbers in each class are shown in Table 1.

The clearest result is the consistent difference in mosaicism rates between crosses (i) and (iii). The males examined for mosaicism of $s n^{v w}$ in these crosses have the same zygotic genotypes, but differ in that, while their mothers all possess $M o$, in cross (i) the mothers have $s n^{v w}$ whereas, in cross (iii), the mothers have the $s n^{+}$allele on their attached-X chromosomes. The average mosaicism rate in cross (i) is 10.03 per cent (based on $1575 s n^{v w}$ males) whereas in cross (iii) it is 33.6 per cent (based on 631 males). In five repeats out of five the difference goes in the same direction (which is itself significant at the 5 per cent level in a one-tailed test). Within 
each of the five repetitions the proportions of mosaics in crosses (i) and (iii) are very significantly different in $G$-tests. However, in this experiment, as in earlier ones with this system, females which all possess $M o$ nevertheless show significant variability in the proportions of mosaics in their male offspring.

Table 1 Phenotypes of $F_{2}$ males

\begin{tabular}{|c|c|c|c|c|}
\hline $\begin{array}{l}\text { Cross } \\
\text { number }\end{array}$ & $\begin{array}{c}\text { Mosaic } s n^{\nu w} \\
\text { males }\end{array}$ & $\begin{array}{l}\text { Nonmosaic } \\
s n^{v w} \text { males }\end{array}$ & $s n^{e}$ males & $s n^{+}$males \\
\hline \multicolumn{5}{|l|}{ Male 1} \\
\hline (i) & 32 & 207 & 2 & 2 \\
\hline (ii) & 0 & 370 & 4 & 18 \\
\hline (iii) & 58 & 55 & 0 & 0 \\
\hline \multicolumn{5}{|l|}{ Male 2} \\
\hline (i) & 38 & 230 & 0 & 35 \\
\hline (ii) & 0 & 360 & 7 & 7 \\
\hline (iii) & 58 & 79 & 0 & 0 \\
\hline (iv)* & 0 & 167 & 2 & 5 \\
\hline \multicolumn{5}{|l|}{ Male 3} \\
\hline (i) & 46 & 555 & 0 & 6 \\
\hline (ii) $\dagger$ & 2 & 766 & 12 & 2 \\
\hline (iii) & 52 & 181 & 0 & 0 \\
\hline (iv) & 0 & 365 & 5 & 4 \\
\hline \multicolumn{5}{|l|}{ Male 4} \\
\hline (i) & 8 & 153 & 15 & 4 \\
\hline (ii) & 0 & 301 & 5 & 5 \\
\hline (iii) & 19 & 46 & 0 & 0 \\
\hline (iv) $\ddagger$ & 0 & 114 & 4 & 1 \\
\hline \multicolumn{5}{|l|}{ Male 5} \\
\hline (i) & 34 & 272 & 2 & 1 \\
\hline (ii) & 0 & 180 & 2 & 8 \\
\hline (iii) & 25 & 58 & 0 & 0 \\
\hline (iv) & 1 & 198 & 2 & 0 \\
\hline
\end{tabular}

*Also contains one male more extreme singed than $s n^{e}$. $\dagger$ Also contains 2 males more extreme singed than $s n^{e}$, plus one male more extreme than $s n^{v w}$ but less extreme than $s n^{e}$.

\$Also contains one forked male (caused by breaking of the mother's attached-X yellow forked chromosome).
This means that individual $\mathrm{F}_{2}$ males are not independent samples. To overcome this problem, I have calculated the proportion of mosaics in the sons of $\mathrm{F}_{1}$ females in crosses (i) and (iii), and compared the females using the nonparametric Mann-Whitney $U$-test. This test takes all females in crosses (i) and (iii) and ranks them according to the proportions of mosaic sons which they produce. The null hypothesis is that females from the crosses (i) and (iii) are randomly distributed with respect to this ranking. The results of the Mann-Whitney test are given in Table 2.

These tests reveal significance more mosaics in cross (iii) for males 1, 2, 4 and 5. For male 3 the data diverge from the null hypothesis in the same direction, but narrowly miss significance $(P=0.054)$. With respect to male 3 two females in cross (iii), surprisingly, show no mosaic males in their offspring, despite the large number of males examined (42 and 44 , respectively). This is surprising as the lack of recombination in males implies that these females should, like their sisters, have possessed Mo. This may be a sign of male recombination in the region, separating $\mathrm{Mo}$ from $\mathrm{pr}^{+}$(although recent experiments looking for male recombination in the presence of $M o$ gave rates under 0.1 per cent (J. F. Y. Brookfield, et al., unpublished data)). Alternatively, it could be a sign of instability of the Mo mutation itself.

The data for germline reversion in males and females in Table 1 give no clear evidence for a reduction in the rate of reversion in females in cross (i) relative to males in crosses (ii) and (iv). The similarity of rates in crosses (ii) and (iv) gives reassurance that the $s n^{v w}$ in strains 1 and 2 (being tested in (i), (iii) and (iv)) behaves exactly the same as that in strain 3 (being tested in (i) and (ii)). There is a problem with these data, however. The reversions of $s n^{v \omega}$ to $s n^{e}$ and $s n^{+}$products are clustered in males but much more strongly clustered in females. For male 2, for example, there are a very large number of pseudo-wild-type $F_{2}$ males in cross (i). Of

Table 2 Mann-Whitney $U$-tests to compare mosaicism in crosses (i) and (iii)

\begin{tabular}{lcccc}
\hline $\begin{array}{l}\text { Male } \\
\text { number }\end{array}$ & $\begin{array}{c}\mathrm{F}_{1} \text { females } \\
\text { tested-cross (i) }\end{array}$ & $\begin{array}{c}\mathrm{F}_{1} \text { females } \\
\text { tested-cross (iii) }\end{array}$ & $\begin{array}{c}\text { Value of test } \\
\text { statistic } U\end{array}$ & $\begin{array}{c}\text { Probability } \\
\text { (two-tailed) }\end{array}$ \\
\hline 1 & 9 & 7 & 63 & 0.0010 \\
2 & 19 & 7 & 116 & 0.0045 \\
3 & 20 & 7 & 105 & 0.0541 \\
4 & 16 & 6 & 84.5 & 0.0021 \\
5 & 17 & 8 & 102.5 & 0.0471 \\
\hline
\end{tabular}


these, 15 males are from a single female, who only produced 13 unreverted $s n^{\nu \omega}$ male offspring. The simplest explanation is that this female was actually heterozygous for $s n^{\nu w}$ and its $s n^{+}$product, having received a $s n^{+}$allele from her father (who could have had reversions in his germline). The problem is that such heterozygotes (and indeed $s n^{\nu w} / s n^{e}$ heterozygotes), cannot be reliably distinguished from $s n^{\nu w}$ homozygotes. This means that the observed $s n^{v w}$ reversion rate in these females is actually the sum of their reversion rates and those of their $s n^{\nu w}$ fathers. Similarly, the fourth male gave many $s n^{e} \mathrm{~F}_{2}$ males in cross (i), but in one case six of $16 \mathrm{~F}_{2}$ males were $s n^{e}$, and in another case four of seven were. Again the $F_{1}$ females tested were probably heterozygotes.

To overcome these artefacts, I examined all the offspring in cross (i), and scored only the numbers of $s n^{\nu w}$ and revertant males for all females where the proportions of revertants (of each of the two revertant classes) were significantly less than half. This was designed to eliminate cases where the mother was not homozygous for $s n^{v w}$. Clearly, this procedure will introduce a downward bias in the reversion rate, and so the same procedure was applied to the results of crosses (ii) and (iv), so that the data remained comparable. The results of this procedure are given in Table 3 .

If, in the adjusted data, crosses (ii) and (iv) are pooled, and the average compared with the cross (i) results, the total rate of reversion in males is 50 per cent higher than in females ( 3.3 per cent vs. 2.2 per cent). However, it is impossible to treat individual $F_{2}$ revertant males as independent observations, as they occur in clusters derived from single reversion events in their mothers or fathers. No significant evidence for a reduced rate in females comes from these data. The rates in males are broadly similar to those seen earlier (5.5 per cent total reversion rate in the presence of zygotic but not maternal Mo (J. F. Y. Brookfield et al., unpublished data).

Three mosaic males were observed in crosses (ii) and (iv), which are difficult to explain as these $s n^{\nu w}$ males would not have had Mo mothers. If they do not represent errors in scoring then they may indicate a low level of somatic reversion resulting from a zygotic effect of the Mo allele (as all three males had this).

\section{Discussion}

There is a very clear and significant reduction in the level of mosaicism of $s n^{\nu \omega}$ in cross (i) relative to cross (iii). The males that are being examined for mosaicism in these crosses have the same genotype and differ only in the genotypes of their mothers. The threefold reduction in mosaicism rate observed must, therefore, be caused by the substitution of the $s n^{v w}$-bearing $\mathrm{X}$ chromosome for the attached-X chromosome. The $s n^{v w}$ chromosome was originally from Canton S, a pure $M$ strain, and thus lacked $P$ elements (Brookfield \& Mitchell, 1985). We have no knowledge of any $\mathrm{P}$ elements on this chromosome other than the two at $s n^{v w}$. It seems probable that the attenuation of mosaicism in the $F_{1}$ results from the effects of these $\mathrm{P}$ elements at singed. One could imagine that this effect is a form of transposase titration (Simmons \& Bucholz, 1985; Simmons et al., $1987,1990)$, in which it is the binding, in the mother, of a $\mathrm{P}$ product from $M o$ to the X-linked $\mathrm{P}$ elements that makes this product unavailable for incorporation into the egg, and thus reduces the level of excision in the zygote. Two arguments can be raised against such a transposase titration model. First, the titration of the transposase that will make it unavailable to destabilize $s n^{v w}$ does not happen simultaneously with $s n^{v w}$ reversion. The $s n^{v w}$ allele in the

Table 3 Reversion rates in males and females. (a) Proportions of revertants in crosses (i), (ii) and (iv) pooled across all five original males. (b) Proportions of revertants in crosses (i), (ii) and (iv) following adjustment

\begin{tabular}{|c|c|c|c|c|c|}
\hline Cross & $s n^{\nu w}$ males & $s n^{e}$ males & $s n^{+}$males & $\begin{array}{l}\text { Other } \\
\text { revertants }\end{array}$ & $\begin{array}{l}\text { Total reversion } \\
\text { rate }(\%)\end{array}$ \\
\hline \multicolumn{6}{|l|}{ (a) } \\
\hline (i) & 1575 & 19 & 48 & 0 & 4.1 \\
\hline (ii) & 1979 & 30 & 40 & 3 & 3.6 \\
\hline (iv) & 785 & 13 & 10 & 1 & 3.0 \\
\hline \multicolumn{6}{|l|}{ (b) } \\
\hline (i) & 1486 & 4 & 30 & 0 & 2.2 \\
\hline (ii) & 1948 & 27 & 40 & 3 & 3.5 \\
\hline (iv) & 762 & 13 & 10 & 1 & 3.1 \\
\hline
\end{tabular}


mother to which the transposase from $M o$ is hypothesized to bind will itself be passed into the oocyte, and thus, if the transposase is subsequently released, this binding will not reduce the availability of the Mo product for the zygotic excision process. Secondly, the size of the mosaic patches in the sons reveals that the excisions do not commence at fertilization, but after a number of cell divisions (Brookfield \& Lewis, 1989), when there are hundreds of nuclei. It is hard to imagine the two copies of $s n^{v w}$ in the mother significantly reducing, by a titration effect, the transposase available to the hundreds of $s n^{v w}$ copies in the $\mathrm{F}_{1}$ at the time of destabilization.

The data seem more consistent with the idea that KP transcription, which results from the element's presence in singed, reduces in some way the effective level of Mo product in the oocyte. This could be by reducing the level of $M o$ put into the egg, perhaps by an effect on $M o$ transcription, or by including a $\mathrm{KP}$ product in the egg that antagonizes the Mo product in the zygotic nuclei.

There is, however, nothing in this experiment that demonstrates that the level of repression induced by the KP element is any higher than that induced by other deleted $\mathrm{P}$ elements of similar or greater size. Indeed, perhaps the most obvious characteristic of the repression is that it still allows 10.03 per cent of offspring to be visibly mosaic. Indeed, there is no demonstration that it is the KP element in $s n^{v w}$ that is generating the repression. Rasmusson et al. (1993) found that a very short $\mathrm{P}$ element, SP, of 517 base pairs, was capable of eliciting a strong repression of $s n^{w}$ reversion and of gonadal dysgenesis, despite the fact that the predicted polypeptide encoded would contain only 14 amino acids. These authors suggest that the SP sequence could repress through the formation of an antisense P RNA by way of readthrough from an external promoter. Interestingly, $s n^{v w}$ also has a short element which would be transcribed from the wrong strand by transcription initiating at the singed promoter. Nevertheless, in view of the earlier observation that KP may be capable of repression in other systems, and of the absence of any evidence of such repression arising from the other element in $s n^{v w}$, the most parsimonious explanation for the effect noted here is an effect of KP itself.

\section{Acknowledgements}

I thank Evelyn Gurd for excellent technical assistance and Richard M. Badge for many useful discussions. This work has received support from the SERC and the NERC.

\section{References}

ANXOlabÉHÈre, D., KIDWEll, M. G. AND PERIQUeT, G. 1988. Molecular characteristics of diverse populations are consistent with a recent invasion of Drosophila melanogaster by mobile P elements. Mol. Biol. Evol., 5, 252-269.

BLACK, D. M., JACKSON, M. S., KIDWELL, M. G. AND DOVER, G. A. 1987. KP elements repress P-induced hybrid dysgenesis in Drosophila melanogaster. EMBO. J., 6, 4125-4135.

BROOKFIELD, J. F. Y. 1991. Models of repression of transposition in $\mathrm{P}-\mathrm{M}$ hybrid dysgenesis by $\mathrm{P}$ cytotype and by zygotically encoded repressor proteins. Genetics, 128, $471-486$.

BROOKFIELD, J. F. Y. AND LEWIS, A. P. 1989. Somatic reversion of $\mathbf{P}$ transposable element insertion mutations in the singed locus of Drosophila melanogaster requiring specific P-insertions and a trans-acting factor. Genet. Res., 54, 101-112.

BROOKFIELD, J. F. Y. AND MITCHELL, S. F. 1985. P-M hybrid dysgenesis using geographically separate $\mathbf{P}$ strains of Drosophila melanogaster. Heredity, 55, 163-165.

ENGELS, w. R. 1979. Extrachromosomal control of mutability in Drosophila melanogaster. Proc. Natl. Acad. Sci. U.S.A., 76, 4011-4015

ENGELS, w. R. 1989. P elements in Drosophila melanogaster. In: Berg, D. E. and Howe, M. M., (eds) Mobile $D N A$, pp. 437-484. American Society for Microbiology, Washington, DC.

ENGELS, W. R., JOHNSON-SCHLITZ, D. M., EGGLESTON, W. B. AND SVED, J. 1990. High-frequency $P$ element loss in Drosophila is homolog dependent. Cell, 62, 515-525.

GLOOR, G. B., NASSIF, N. A., JOHNSON-SCHLITZ, D. M., PRESTON, C. R. AND ENGELS, W. R. 1991. Targeted gene replacement in Drosophila via $\mathbf{P}$ element-induced gap repair. Science, 253, 1110-1117.

GLOOR, G. B., PRESTON, C. R., JOHNSON-SCHLITZ, D. M., NASSIF, N. A., PHILliS, R. W., BENZ, W. K., ROBERTSON, H. M. AND ENGELS, w. R. 1993. Type I repressors of $P$ element mobility. Genetics, 135, 81-95.

HEATH, E. M. AND Simmons, M. J. 1991. Genetic and molecular analysis of repression in the $\mathrm{P}-\mathrm{M}$ system of hybrid dysgenesis in Drosophila melanogaster. Genet. Res., 57, 213-226.

Higuet, D., ANXOlabÉHER̀E, D. AND NOUAud, D. 1992. A particular P-element insertion is correlated to the $\mathrm{P}$-induced hybrid dysgenesis repression in Drosophila melanogaster. Genet. Res., 60, 15-24.

JACKSON, M. S., BLACK, D. M. AND DOVER, G. A. 1988. Amplification of $K P$ elements associated with the repression of hybrid dysgenesis in Drosophila melanogaster. Genetics, 120, 1003-1013.

LASKI, F. A. AND RUBIN, G. M. 1989. Analysis of the cis-acting requirements for germ-cell specific splicing of the $\mathrm{P}$ element ORF2-ORF3 intron. Genes Devel., 3, 720-728.

LASKl, F. A., RlO, D. C. AND RUBIN, G. M. 1986. Tissue specificity of Drosophila $\mathrm{P}$ element transposition is regulated at the level of mRNA splicing. Cell, 44, 7-19. 
LEMAITRE, B. AND COEN, D. 1991. $P$ regulatory products repress in vivo the $P$ promoter activity in $P$-lac $Z$ fusion genes. Proc. Natl. Acad. Sci. U.S.A., 88, 4419-4423.

LEMAITRE, B., RONSSERAY, S. AND COEN, D. 1993. Maternal repression of the $P$ element promoter in the germline of Drosophila melanogaster: a model for the P cytotype. Genetics, 135, 149-160.

MISRA, S. AND RIO, D. C. 1990. Cytotype control of Drosophila $\mathrm{P}$ element transposition: the $66 \mathrm{kd}$ protein is a repressor of transposase activity. Cell, 62, 269-284.

MONASTIRIOTI, M., HATZOPOULOS, P., STAMATIS, N., YANNOPOULOS, G. AND LOUIS, C. 1988. Cohabitation of KP and full-length $P$ elements in the genome of $M R$ strains inducing $P$-M-like hybrid dysgenesis in Drosophila melanogaster. Mol. Gen. Genet., 215, 94-99.

NASSIF, N., PENNEY, J., PAL, S., ENGELS, W. R. AND GLOOR, G. B. 1994. Efficient copying of nonhomologous sequences from ectopic sites via P-element-induced gap repair. Mol. Cell. Biol., 14, 1613-1625.

O'HARE, K. AND RUBIN, G. M. 1983. Structures of P transposable elements and their sites of insertion and excision in the Drosophila melanogaster genome. Cell, 34, 25-35.

o'KANE, C. J. AND GEHRING, w. 1987. Detection in situ of genomic regulatory elements in Drosophila. Proc. Natl. Acad. Sci. U.S.A., 84, 9123-9127.

ORTORI, C. A., CHAMBERS, D. AND BROOKFIELD, J. F. Y. 1994. The molecular basis of instability of the singed very weak mutation in Drosophila melanogaster. Genet. Res., 63, 19-26.

PATERson, J. AND o'hare, K. 1991. Structure and transcription of the singed locus of Drosophila melanogaster. Genetics, 129, 1073-1084.
RASMUSSON, K. E., RAYMOND, J. D. AND SIMMONS, M. J. 1993. Repression of hybrid dysgenesis in Drosophila melanogaster by individual naturally occuring $P$ elements. Genetics, 133, 605-622.

RAYMOND, J. D., OJALA, T. A., WHITE, J. AND SIMMONS, M. J. 1991. Inheritance of $P$-element regulation in Drosophila melanogaster. Genet. Res., 57, 227-234.

Roiha, H., RUbin, G. M. AND o'hare, K. 1988. $P$ element insertions and rearrangements at the singed locus of Drosophila melanogaster. Genetics, 119, 75-83.

RONSSERAY, S., LEHMANN, M. AND ANXOLABÉHÈRE, D. 1991. The maternally inherited regulation of $P$ elements in Drosophila melanogaster can be elicited by two $P$ copies at cytological site $1 \mathrm{~A}$ on the $X$ chromosome. Genetics, 129, 501-512.

SIEBEL, C. W., FRESCO, L. D. AND R1O, D. C. 1992. The mechanism of somatic inhibition of Drosophila $P$ element pre-mRNA splicing: multiprotein complexes at an exon pseudo-5' splice site control U1 snRNP binding. Genes Devel., 6, 1386-1401.

simmons, M. J. AND BUCHOLz, L. M. 1985. Transposase titration in Drosophila melanogaster: A model of cytotype in the $P-M$ system of hybrid dysgenesis. Proc. Natl. Acad. Sci. U.S.A., 82, 8119-8123.

SIMMONS, M. J., RAYMOND, J. D., BOEDIGHEIMER, M. J. AND zUNT, J, R. 1987. The influence of nonautonomous $P$ elements on hybrid dysgenesis in Drosophila melanogaster. Genetics, 117, 671-685.

SIMMONS, M. J., RAYMOND, J. D., RASMUSSON, K. E., MILLER, L. M., McLARNON, C. F. AND ZUNT, J. R. 1990. Repression of $P$ element-mediated hybrid dysgenesis in Drosophila melanogaster. Genetics, 124, 663-676. 